\title{
Mapping intracerebral steal during a hypercapnic challenge
}

\author{
Sujoy Banik, MBBS, MD, DM • Joseph A. Fisher, MD $\cdot$ Larissa McKetton, PhD • \\ Lashmi Venkatraghavan, MD, FRCA, FRCPC
}

Received: 1 June 2017/Revised: 6 July 2017/Accepted: 13 July 2017/Published online: 17 July 2017

(C) Canadian Anesthesiologists' Society 2017

In patients with intracranial steno-occlusive disease, blood vessels distal to the stenosis are in a state of maximum compensatory vasodilation to maintain cerebral perfusion. With a global cerebral vasodilatory stimulus such as hypotension or hypercapnia, blood vessels in the nonaffected areas often vasodilate, causing intracerebral "steal" (ICS) of the blood flow away from the affected area, increasing the risk of cerebral ischemia (and subsequent stroke). ${ }^{1}$ Mapping of ICS could potentially be used as a tool to assess patients for the risk for stroke. ${ }^{1,2}$

Using blood oxygen level-dependent magnetic resonance (BOLD-MR) imaging as a surrogate of cerebral blood flow (CBF) and $\mathrm{CO}_{2}$ as a vasodilatory stimulus, we developed a non-invasive method to map ICS. Here, we present the cerebrovascular reactivity $-\Delta \mathrm{CBF} / \Delta$ end-tidal $\mathrm{CO}_{2}\left(\mathrm{P}_{\mathrm{ET}} \mathrm{CO}_{2}\right)$ - map of a 29 -yr-old patient with $90 \%$ stenosis of the left proximal middle cerebral artery. The BOLD MR images were obtained while $\mathrm{P}_{\mathrm{ET}} \mathrm{CO}_{2}$ was controlled in a ramp sequence (see Figure) from 35 to 52 $\mathrm{mmHg}$ using a sequential breathing circuit and a computer- controlled gas blender (RespirAct ${ }^{\mathrm{TM}}$, Thornhill Research, Inc., Toronto, ON, Canada). ${ }^{3}$ Using custom software, colour cerebrovascular reactivity maps are generated that indicate areas of normal (red) and paradoxical (i.e., steal) (blue) reactivity. The cerebrovascular reactivity values were measured as \% BOLD-MR signal intensity per mmHg change in $\mathrm{P}_{\mathrm{ET}} \mathrm{CO}_{2}$.

As the $\mathrm{P}_{\mathrm{ET}} \mathrm{CO}_{2}$ increases from 35 to $42 \mathrm{mmHg}$, steal (blue areas) develops on the left side of the brain, with normal reactivity on the right side (Figure, MR image A). With further increases in $\mathrm{P}_{\mathrm{ET}} \mathrm{CO}_{2}$ (from 42 to $52 \mathrm{mmHg}$ ) more steal appears on the left side (Figure, MR image B). Finally, a return to normocapnia results in a symmetrically opposite effect, with reverse steal on the healthy right side and increased blood flow to the compromised vascular bed on the left (Figure, MR image C). Understanding ICS may be important during perioperative care of patients with intracranial stenosis as both hypercapnia and hypotension could lead to hemodynamically mediated stroke.

S. Banik, MBBS, MD, DM · J. A. Fisher, MD .

L. McKetton, $\mathrm{PhD} \cdot$ L. Venkatraghavan, MD, FRCA, FRCPC ( $\square)$

Department of Anesthesia and Medical Imaging, Toronto

Western Hospital, University Health Network, University of

Toronto, Toronto, ON, Canada

e-mail: lashmi.venkatraghavan@uhn.ca 
Figure Graph shows changes in the partial pressure of endtidal carbon dioxide $\left(\mathrm{P}_{\mathrm{ET}} \mathrm{CO}_{2}\right)$ over time (top) along with the corresponding cerebrovascular reactivity (CVR) determined using blood oxygen leveldependent magnetic resonance (BOLD-MR) imaging (bottom). Arrows indicate the level of $\mathrm{P}_{\mathrm{ET}} \mathrm{CO}_{2}$ where the corresponding cerebrovascular reactivity (CVR) images below were obtained using blood oxygen level-dependent magnetic resonance imaging. The color coding depicts the CVR (blue areas: intracranial steal; red areas: normal reactivity). A) BOLD-MR CVR image when $\mathrm{P}_{\mathrm{ET}} \mathrm{CO}_{2}$ is between 35 and $42 \mathrm{mmHg}$. Intracranial steal has developed on the left side with normal reactivity on the right. B) BOLD-MR CVR image when $\mathrm{P}_{\mathrm{ET}} \mathrm{CO}_{2}$ is between 42 and $52 \mathrm{mmHg}$. Note the intensification of intracranial steal on the left side with increasing $\mathrm{P}_{\mathrm{ET}} \mathrm{CO}_{2}$. C) BOLDMR CVR image when $\mathrm{P}_{\mathrm{ET}} \mathrm{CO}_{2}$ is between 40 and $52 \mathrm{mmHg}$. With the return to normocapnia, reverse steal is occurring on the right side of the brain along with improved reactivity on the left side

Acknowledgement The authors acknowledge the important role of the University Health Network-Cerebrovascular Reactivity (UHNCVR) Group in the development of this innovation.

Conflicts of interest None declared by Sujoy Banik and Larissa McKetton. Joseph A. Fisher: Respiract ${ }^{\mathrm{TM}}$ is currently a noncommercial research tool assembled and made available by Thornhill Research Inc. (TRI), a spin-off company from the University Health Network (UHN), to research institutions to enable CVR studies. JAF is the chief scientist and contributed to the development of Respiract ${ }^{\mathrm{TM}}$ and has received payment from, or shares in, TRI. Lashmi Venkatraghavan: MSH-UHN AMO AFP Innovation Fund 2013-15.

Editorial responsibility This submission was handled by Dr. Hilary P. Grocott, Editor-in-Chief, Canadian Journal of Anesthesia.
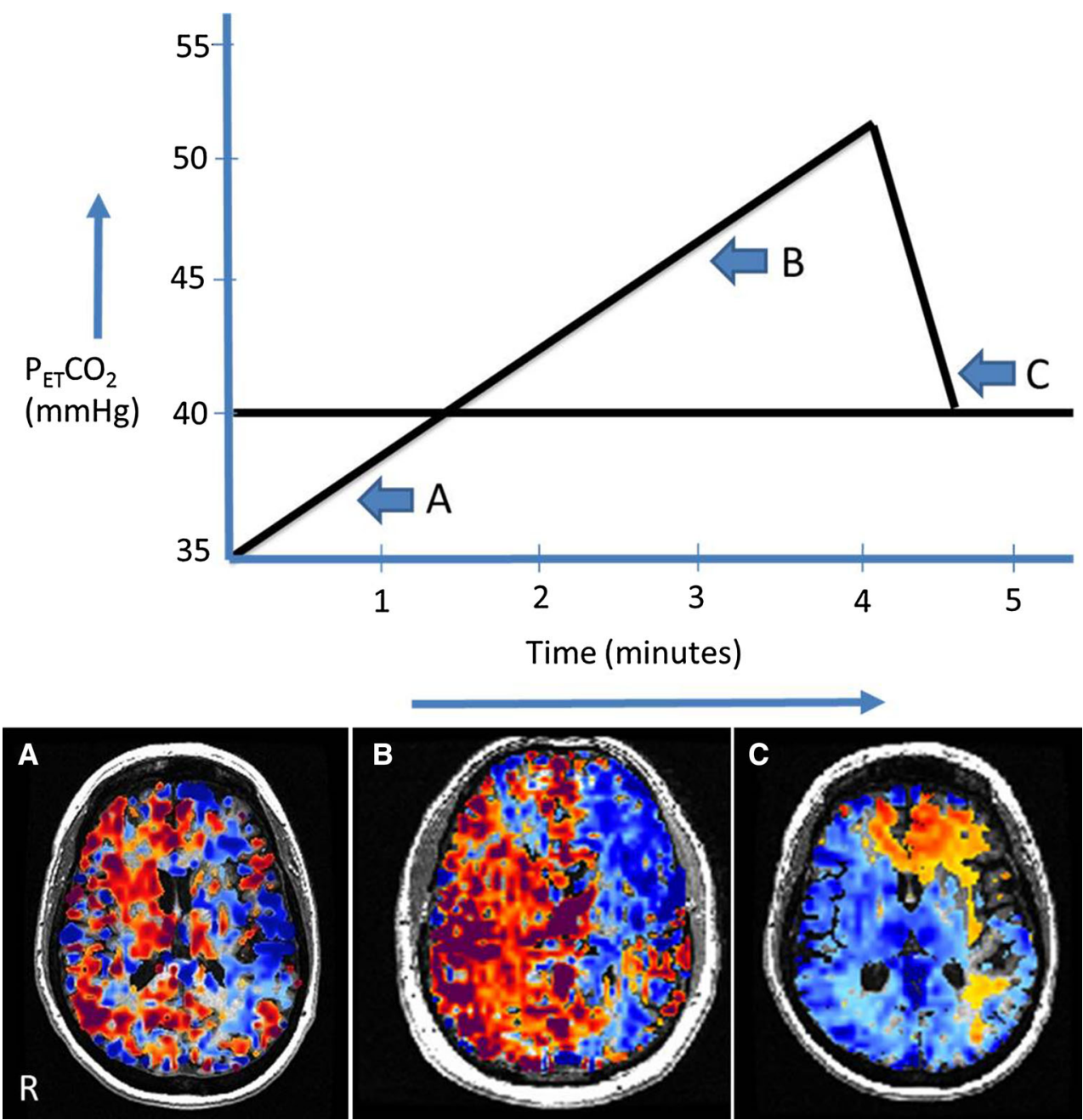

Funding This study was funded in part by a grant from MSH-UHN AMO AFP Innovation fund 2013-15

\section{References}

1. Kim TJ, Lee JS, Hong JM, Lim YC. Intracerebral steal phenomenon: a potential mechanism for contralateral stroke after carotid artery stenting. The Neurologist 2012; 18: 128-9.

2. Alexandrov AV, Nguyen HT, Rubiera M, et al. Prevalence and risk factors associated with reversed Robin Hood syndrome in acute ischemic stroke. Stroke 2009; 40: 2738-42.

3. Sam K, Peltenburg B, Conklin J, et al. Cerebrovascular reactivity and white matter integrity. Neurology 2016; 87: 2333-9. 